\title{
DESIGN OF AN AUTOMATIC TOOL CHANGER SYSTEM FOR MILLING MACHINING CENTERS
}

\author{
OBREA, C[laudiu] F[lorin]; PASCU, M[arius]; MIHAILA, L[ucian] \& FUNARU, M[arian]
}

\begin{abstract}
In the field of manufacturing processes it is observed that the trend is to produce more and more faster, efficiently parts with high complexity, which involves using a high number of tools in the machining process. One of the main solutions for high speed and efficient manufacturing is based on the full automation of the entire manufacturing process. The automatic changing of the tools involved in the manufacturing process is carried out by the automatic tool changing mechanism, thus the auxiliary non-productive time consumed with the tool change is highly minimized. In this paper we present a novel automatic tool changer which is both simple and compact, and any milling machining center provided with chain or disc tool magazine can be equipped with. Also by adopting the use of this tool changing mechanism other subassemblies of the tool changing system, such as the tool transfer mechanism and the waiting position, are substituted by this changing mechanism. The auxiliary movements needed to bring the tool from the magazine into the waiting position are overlapped with the machining time, so that the total time for exchanging the tool in the spindle with the tool from the magazine is minimized.

Key words: automatic tool changer, milling machining center, mechanical arm, tool magazine, auxiliary time, auxiliary movements
\end{abstract}

\section{INTRODUCTION}

The full automation of manufacturing processes in metal cutting industry is possible today through implementing in the structure of machining centers of automatic tool changer mechanisms. Their role is, on one side, to reduce the auxiliary nonproductive times by replacing automatically the tools involved in the machining process and, on the other side, to make possible the machining of more complex parts through ensuring the necessary tools.

The smooth run of the technological process on machining centers is ensured by the automatic tool changers (ATC) through the complete automation of the tool change operation sequence (the path followed by the tool from the magazine to the spindle and vice versa). Because of the actual requirements regarding the high complexity of parts to be manufactured, the automatic tool changing systems must meet, mainly, two conditions: to be able to store a large number of tools in the magazine, which can be achieved by using chain type magazines, and to reduce the auxiliary time needed to exchange the tool to follow the technological process with the purpose to minimize the total machining time.

According to the actual state in the field of automatic tool changer systems which equip machining centers, the existent constructive solutions of ATC's are various regarding their design and running principles, according to the subassemblies from which these systems consist of [1].

The main component modules of which the ATC systems consist of are:

- Tool magazine;

- Tool transfer mechanism;

- Parking station;

- ATC arm;

- Tool clamp mechanism (spindle).

A classification of automatic tool changing systems according to the component modules was made by Yan in [2] where these systems have been classified in five different constructive solutions. Chen presented in [3] a method for synthesizing all possible configurations for three axes horizontal machine centers equipped with automatic tool changers, depending on the topology and relative motion between subunit components. Based on this method, Constantin, in [4] accomplished a synthesis of all possible configurations for three axes vertical machine centers equipped with automatic tool changers systems.

A new constructive solution of an automatic tool changing mechanism operated by a cam mechanism and its operational principles were presented by Cong in [5]. After analyzing several different automatic tool changing systems and their main characteristics, Gokler in [6] presented the operation sequence and the steps to design an automatic tool changer system composed of an disc type magazine without a tool change arm for horizontal machining centers. In this case the automatic tool change is achieved by rotating the disc type magazine with a storage capacity of 24 tools, maximum tool diameter 150 $[\mathrm{mm}]$, maximum tool weight $8[\mathrm{~kg}]$. The designed automatic tool changer system has a "tool to tool" changing time of 4 seconds. Also Zhang in [7] had presented another automatic tool changer system, driven electromechanical, along with its constructive and functioning scheme, in which the tool is engaged from the tool magazine device by the machining center's spindle. Jinan in [8] presented a new constructive solution of an automatic tool changer system for a milling machine center, its command and control devices.

The constructive solution presented in this paper distinguishes from others through the fact that it can be integrated both in the structure of machining centers equipped with large storage chain type magazines, and also in the structure of machining centers with disc type magazines in which the tool's position is normal to the spindle's axis. The automatic tool changer mechanism 
presented can also perform all the movements included in the tool changing operations sequence (automatic tool change from the magazine to the machining center's spindle), thus replacing the other modules: the transfer mechanism and the waiting post. The total tool changing time is minimized through overlapping auxiliary movements needed to bring the tool from the magazine in the tool changing position. Through the simple design of this automatic tool changer and in consequence of the overlapped auxiliary movements which take place during the machining process both the total manufacturing time and the machining center's tool storage capacity is optimized.

\section{AUTOMATIC TOOL CHANGING SYSTEM DESIGN}

\subsection{Sequential cycle of tool change}

The automatic tool changer system's role is to provide the machining center spindle with the tool to follow the machining process and to bring the tool which exits the machining process in the tool magazine. Considering that the tools axes from the magazine are normal to the spindle axis, for changing the tool to exit the machining process with a new one, the ATC performs the following movements (Fig.1):

Pos. 1 - ATC arm slides to the tool in the magazine (clamps the tool);

Pos. 2 - ATC arm slides outward (extracts the tool from the magazine);

Pos. 3 - ATC arm slides with the new tool into an intermediary position;

Pos. 4 - ATC arm slides inward with the new tool;

Pos. 5 - ATC arm is rotated with $90^{\circ}$ bringing the new tool in changing position (tool axis is parallel to spindle axis);

Pos. 6 - ATC arm slides to tool in spindle (clamps the tool);

Pos. 7 - ATC arm slides outward (extracts the tool from spindle);

Pos. 8 - ATC arm rotates with $180^{\circ}$ (the tool exchange takes place);

Pos. 9 - ATC arm slides inward (new tool is clamped by spindle).

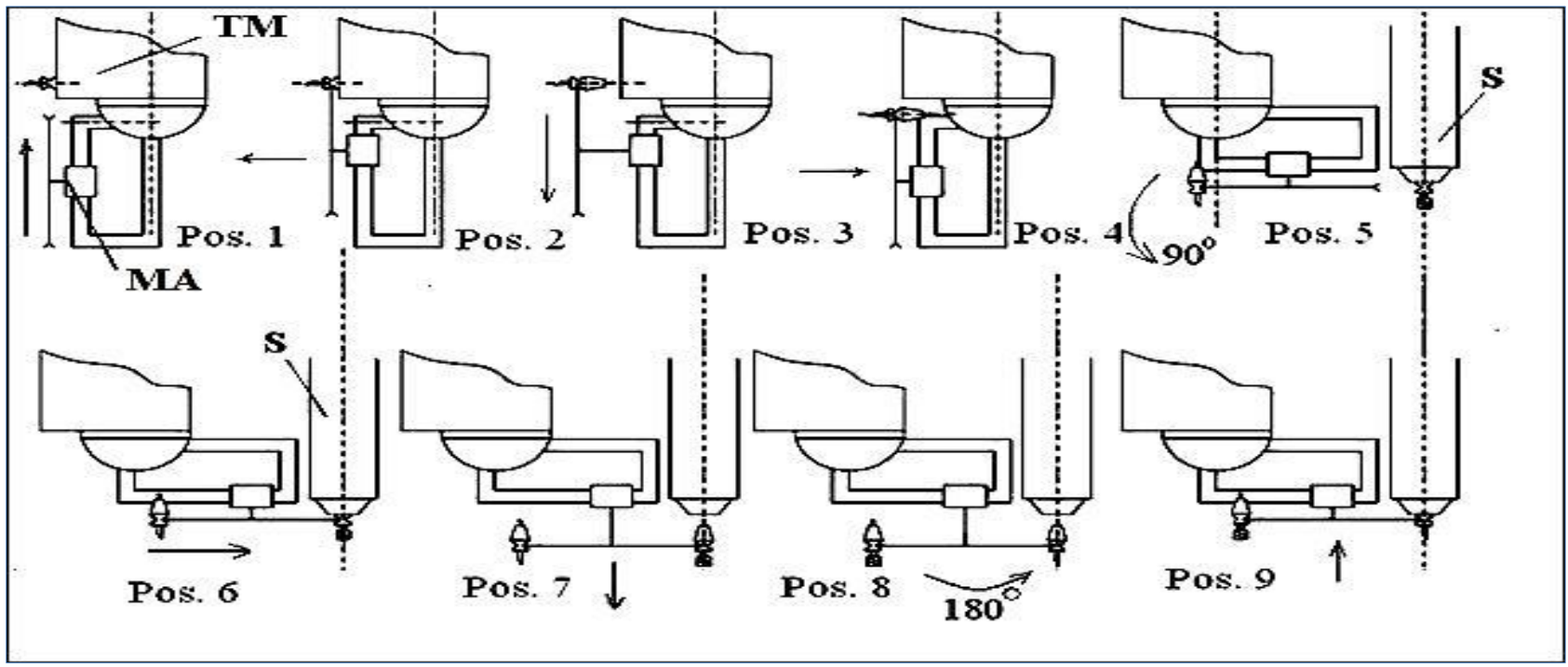

Fig. 1. Schematic tool change sequential cycle; TM - tool magazine device, MA - mechanical arm, S - spindle

The sequential tool change cycle consists of all the movements performed by the ATC mechanism in order to transfer and change a new tool from the magazine with the tool in the spindle. The total time needed to exchange the tool from the spindle or the tool from the magazine is (1):

$$
T_{\text {tot }}=T_{m}+T_{t}+T_{c}
$$

where:

$T_{m}$ - the indexing time of the tool magazine;

$T_{t}$ - the necessary time for bringing the new tool by the ATC mechanism into the waiting position;

$T_{c}$ - the necessary time to exchange the tool taken from the tool magazine with the one in the spindle.

The time needed to bring the new tool from the tool magazine in the waiting position by the automatic tool changer arm is given in (2):

$$
T_{t}=T_{1}+T_{2}+T_{3}+T_{4}+T_{5}
$$

$T_{1}, T_{2}, T_{3}, T_{4}, T_{5^{-}}$are the necessary times for ATC to perform all the movements associated to positions $\mathrm{P} 1$, P2, P3, P4, P5;

Because these movements are performed during the machining process, thus the time needed to bring the tool into the waiting position $\left(T_{t}\right)$ doesn't influence the machining process. This means the machining process being stopped only for the actual tool exchange in spindle (3):

$$
T_{c}=T_{6}+T_{7}+T_{8}+T_{9}
$$

where:

$T_{6}, T_{7}, T_{8}, T_{9}$ - are the necessary times for ATC to perform all the movements to perform the tool exchange in the spindle associated to positions $\mathrm{P} 6, \mathrm{P} 7, \mathrm{P} 8, \mathrm{P} 9$;

Because the auxiliary movements are overlapped with the machining process, the total time for exchanging the tool in the spindle is highly minimized.

where: 


\subsection{Automatic tool changer mechanism constructive and functional description}

In the automatic tool changing system presented the transfer and automatic tools exchange from the magazine to the spindle, and reciprocal, is performed exclusively by the ATC mechanism, so that the other auxiliary mechanisms (transfer mechanism, parking station) are eliminated from the system. The main components of the ATC mechanism are presented in fig. 2 as follows: mechanical arm 1, the carriage 2, guide rail 3, linear hydraulic motor 4 , hydraulic swing motor 5 , shaft 6 , axial roller bearing 7 , and limit switches 8 .

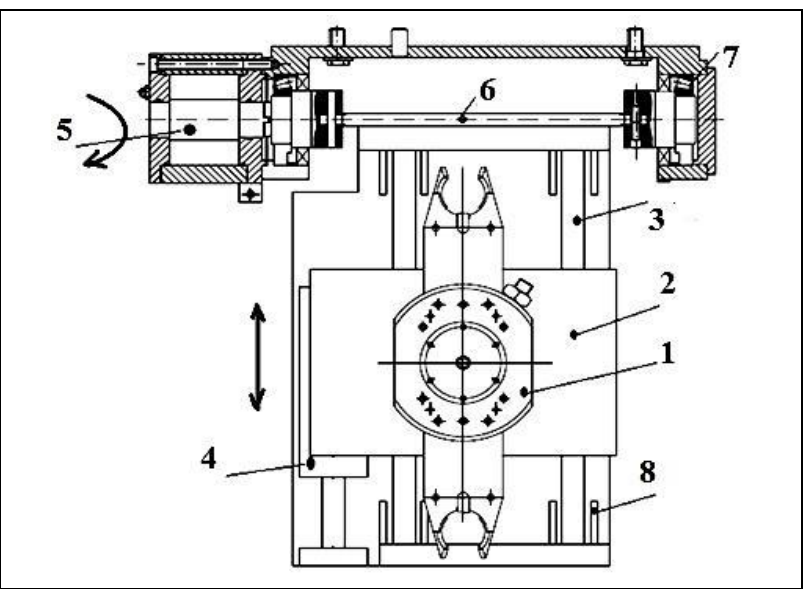

Fig. 2. Automatic tool changer mechanism. Construction

Because the tool axis from the magazine in the changing position is normal to the spindle axis the carriage-guide rail assembly swings with $90^{\circ}$ bringing the mechanical arm in a position parallel to the spindle axis or to the magazine axis. The swing movement with $90^{\circ}$ is driven with the hydraulic swing motor 5 (fig. 2). The construction of this swinging motor is detailed in fig. 3 as follows: housing 1, the rotor of the motor consists in the shaft 2 and the blade 3, throttles 4 . The motor can execute an angular displacement with $90^{\circ}$ in one way or the other depending on the supply way with hydraulic pressure.

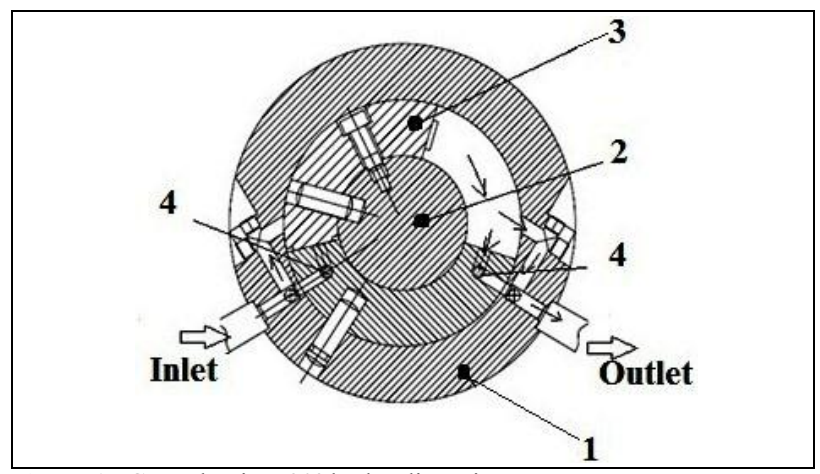

Fig. 3. ATC mechanism $90^{\circ}$ hydraulic swing motor

From functional point of view for displacing the blade to the right, because the blade completely covers the inlet motor chamber, the hydraulic pressure is accessing the chamber through the additional duct (throttle). The throttle plays the role of a flow resistance, moving the blade 3 until it frees the inlet. The passive chamber hydraulic liquid of the motor is evacuated through the outlet duct until it is covered by the blade 3 .
Afterwards the hydraulic liquid is forced to pass through the throttle which role is to damp.

The translation movement (for clamping the tool from the magazine and from the spindle) of the mechanical arm is driven by two hydraulic cylinders serially connected (Fig. 4). The hydraulic cylinder 1 slides the carriage with the mechanical arm on a distance of 100 [mm] to clamp the tool from the magazine and the hydraulic cylinder 2 slides the carriage with the mechanical arm on a distance of 125 [mm] to clamp the tool from the spindle.

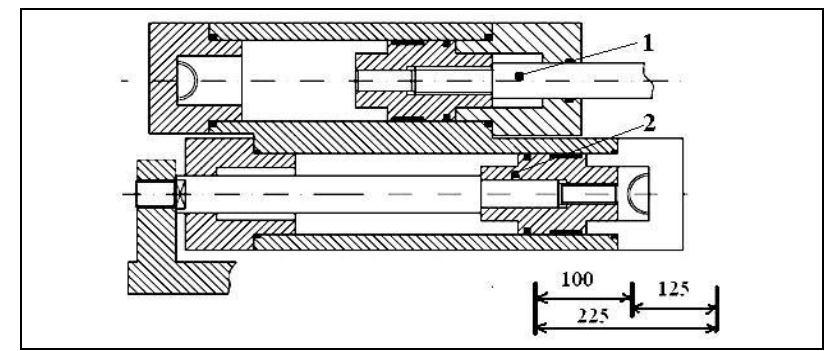

Fig. 4. Serially connected hydraulic cylinder

The role of the mechanical arm from the automatic tool changer mechanism is to extract the tools from the magazine and spindle and exchanging their position in order to allow, in the shortest time, the next tool in the machining process. The main components of the mechanical arm are presented in fig. 5 as follows: carriage 1 , linear hydraulic cylinder 2 , linear hydraulic cylinder 3 , axil roller bearing 4 , guide rail 5 , tool clamping jaws 6 , tool changing arm 7 , and pinion 8 .

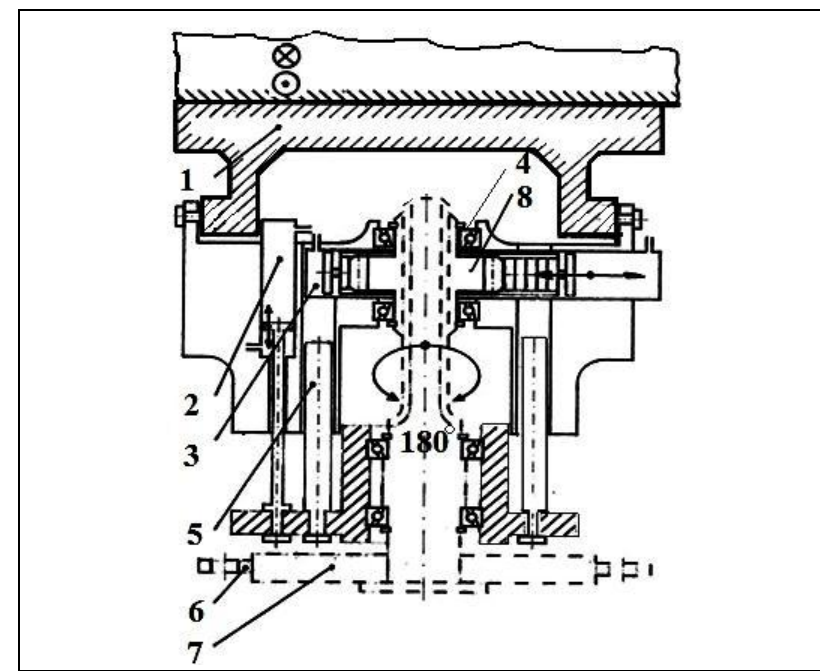

Fig. 5. Automatic tool changer arm

The mechanical arm, from a functional point of view, performs an axial movement (tool in/out operations from/to spindle/tool magazine) driven by the hydraulic cylinder 2 and a swing movement with $180^{\circ}$ for inverting the tool positions. The swing movement is driven by the linear hydraulic cylinder 3 which has a rack executed on its rod that engages pinion 6 mounted on the tool changing arm 7 shaft.

The tool changing arm is provided with jaws for clamping and locking the tools. The tool clamping is performed mechanically by making use of an coiled spring, and the tool unclamping is hydraulically driven as 
it can be seen in the hydraulic drive scheme of the arm in fig. 6 .

Adjusting the mechanical arm movements speed of both translations (tool in/out operations from/to spindle/tool magazine) and rotations (exchanging tool position) is made through the throttles 1 and 2. Changing the movement direction is performed through the solenoid valves 3 and 4 . The tool unclamping is made through the hydraulic cylinders 5 and 6 which are driven by the solenoid valves 7 and 8 . The hydraulic cylinders 5 and 6 return to initial position after the pressure acknowledgment relays 9 and 10 confirm the tool unclamp.

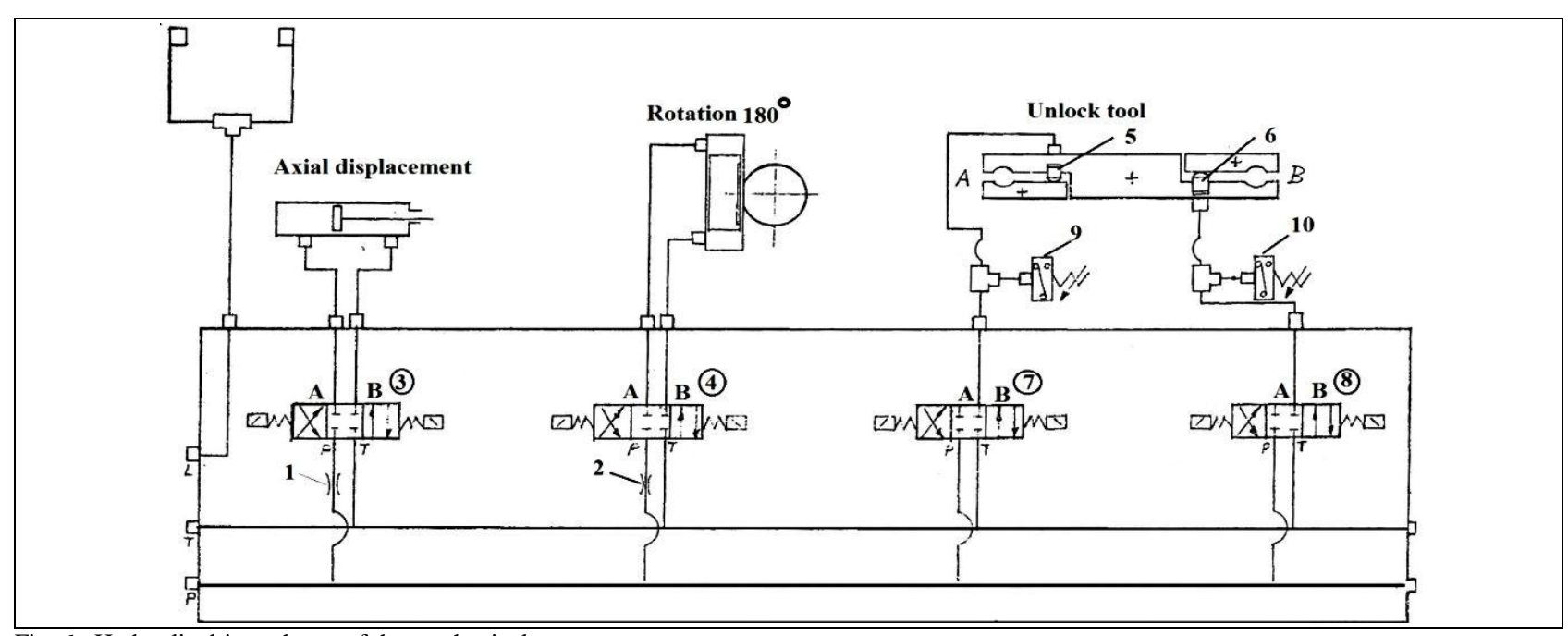

Fig. 6. Hydraulic drive scheme of the mechanical arm

The tool clamp in the in the magazine tool holder is performed mechanically (Fig. 7) with the help of a coiled spring 1; the spring presses the ball 2 which enters groove in tool pull stud 3 .

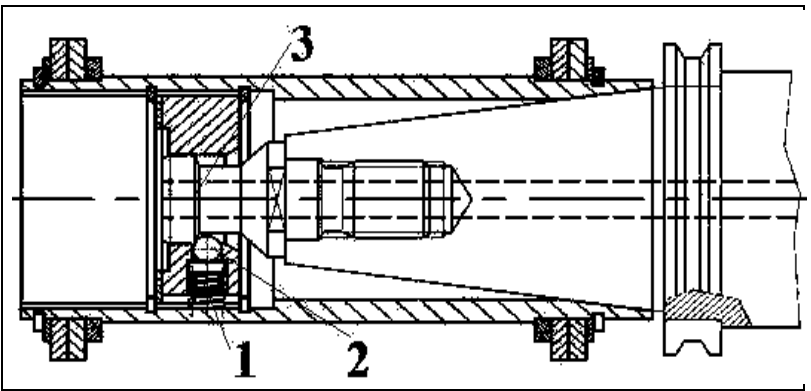

Fig. 7. Tool clamping mechanism in magazine tool holder

\section{CONCLUSIONS}

This ATC mechanism can easily be attached as a module in the milling machining center which is equipped with chain type magazine or disc type magazine where the tool axis is normal to the spindle axis. At the same time, because all the necessary movements are entirely performed by the ATC, the other auxiliary mechanisms (transfer mechanism, parking station) are eliminated from the system's structure. Also, the fact that all the auxiliary movements are performed during the machining process, the "tool to tool" changing time is highly minimized, thus the productivity increases. Because the tool axis from the magazine is normal with the axis of the spindle (the magazine is positioned sideways), the tool storage capacity of the magazine can increase without interfering with the workspace, thus the number of necessary tools is assured for machining parts with high complexity from a single nip.

\section{REFERENCES}

[1] Fleischer, J., Denkena, B., Winfough, B. \& Mori, M., (2006). „Workpiece and Tool Handling in Metal Cutting Machines“, CIRP Annals-Manufacturing Technology, Vol. 55, No. 2, 2006, pp. 817-839

[2] Yan, H. S., Yiou, C.W., Chen, F. C. \& Chang, P., (1995). On the classification of automatic tool changers for machining centers, Proceedings of ASME 1995 Design Engineering Technical Conferences, 1995, USA, Vol. 1, DE (82), pp. 931-936, Boston

[3] Chen F., Yan H. S., (1999). "Configuration Synthesis of Machining Centres with Tool Change Mechanisms", International Journal of Machine Tools \& Manufacture, Vol. 39, No. 2, 1999, pp. 273-295

[4] Constantin, G., Ghionea, A. \& Zapciu, M., (2007). Structural Configuration Methods for Machine Tools, $7^{\text {th }}$ International Multidisciplinary Conference, May 17-18, 2007, Romania, ISSN: 1224-3264, pp. 107-114, Baia Mare

[5] Cong, M., Jing, L.\& Quanpu L., (2008). A Novel Dual-Cam Linkage Drive Automatic Tool Changer for Horizontal Machining Center, Proceedings of the First International Conference on Intelligent Robotics and Applications: Part II, ICIRA 08, 2008, Springer-Verlag Berlin, Heidelberg, ISBN: 978-3-540-88516-0, Xiong, C. et al. (Eds.), pp. 368-377, Berlin

[6] Gokler, M.I., Koc, M.B., (1997). "Design of an automatic tool changer with disc magazine for a CNC horizontal machining center", International Journal of Machine Tools and Manufacture, Vol. 37, No. 3, 1997, pp. 277-286

[7] Zhang, L., Wang, L., (2010). Machining Center Automatic ATC Analysis and Research, Proceedings of 3rd International Conference on Information Management, Innovation Management and Industrial Engineering: Part I, ICIII, November 26-28, 2010, China, ISBN: 978-0-7695-4279-9, pp. 355-358, Kunming

[8] Jinan, G., (2011). Research on the structure and PLC control of a new automatic tool changer, Proceedings of Consumer , Electronics, Communications and Networks, International Conference on Xiang Ning (CECNet), April 16-18, 2011, China, ISBN: 978-1-61284-458-9, pp. 686-689, Xiang Ning 